\title{
Estimations of daily energy and nutrient availability based on nationally representative household budget survey data. The Data Food Networking (DAFNE) project
}

\author{
A Naska ${ }^{1}, E^{2}$ Oikonomou' ${ }^{1}$ A Trichopoulou ${ }^{1,2, *}, \mathrm{~K} \mathrm{Wagner}^{3}$ and K Gedrich ${ }^{3}$ \\ 'Department of Hygiene and Epidemiology, School of Medicine, National and Kapodistrian University of \\ Athens, 75 Mikras Asias Street, Athens 115 27, Greece: ${ }^{2}$ Hellenic Health Foundation: ${ }^{3}$ Department of \\ Marketing and Consumer Research, TUM Business School, Technische Universität München, Munich, Germany
}

Submitted 8 August 2006: Accepted 17 January 2007: First published online 18 June 2007

\begin{abstract}
Objective: To describe a cost-efficient method for estimating energy and nutrient availability using household budget survey (HBS) data.

Design: Four different approaches were tested and the results were compared with published nutrient intake data. The selected method was exemplarily applied in German and Greek data.

Setting: Germany, 1998; Greece, 1998/99.

Material: Nationally representative HBSs.

Results: Comparisons showed that HBS-based estimates were generally close to intake data when results were presented as contributions to daily energy intake. Daily energy and protein availabilities were similar in Germany and Greece. Differences were observed in the availability of carbohydrates (German households reported a 5 percentage points higher contribution to daily energy availability) and lipids (Greek households recorded higher values for total fat, but lower values for saturated fat). Meat, added lipids and potatoes were important energy suppliers in Germany, whereas in Greece the first three energy suppliers were added lipids, cereals and meat. In both countries, meat, cereals, milk and cheese were important protein sources and cereals, potatoes, fruits and nuts contributed more than $60 \%$ of the daily carbohydrate availability. Added lipids were the major source of fat in the daily diet of both countries, but their contribution amounted to less than one-third in Germany and two-thirds in Greece. Conclusions: National HBS data can be used for monitoring and comparing nutrient availability among representative population samples of different countries. The ground is set for the development of a harmonised food composition table to be applied to HBS food data at international level.
\end{abstract}

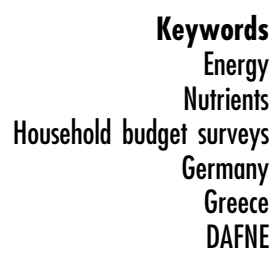

In the realm of actions in the field of public health, the European Commission has been running the Health Monitoring Programme, placing emphasis, among other things, on the promotion of nutrition surveillance in Europe. Within this context, the Directorate General for Health and Consumer Protection (DG-SANCO) has been supporting the development of the Data Food Networking (DAFNE) databank, based on information collected through national household budget surveys (HBSs) ${ }^{1}$.

The DAFNE project has built up a regularly updated food-based databank of currently 16 European countries which allows: (1) the identification of dietary patterns prevailing in Europe and of their sociodemographic determinants $^{2,3}$; (2) the follow-up of time trends in the food habits of European populations ${ }^{4,5}$; and (3) the evaluation of nutrition action plans and related strategies implemented at national or international level ${ }^{6,7}$. At present, the DAFNE coordinating centre is working towards the integration of HBS data collected in new EU Member States (Cyprus, Latvia, Malta, Slovenia and the Slovak Republic) and in West Balkan countries (Albania, Croatia, Serbia and Montenegro), responding to the need for information in order to support the formulation of nutrition strategies in the region.

Data collected through HBSs, which the DAFNE project exploits, have traditionally been used for nutrient analysis at country level ${ }^{8-15}$. In these settings, nutrient estimates are derived with the application of national conversion factors developed and routinely revised ad hoc. However, HBS-based nutrient estimations have not yet been attempted in an international setting. 
The present paper aims to describe a cost-efficient method that could be applied in various countries in order to use the nationally representative HBS food data for comparisons on energy and nutrient estimations. The method is exemplarily applied to data collected in Germany and Greece, and results on the daily availability of energy and macronutrients are presented.

\section{Material and methods}

\section{Data collection in the HBSs}

HBSs are systematically conducted by national statistical offices in country-representative population samples and aim to collect data on food availability at household level. The members of the participating households are asked to record, mainly in open questionnaires, information on all foods and beverages available during a reference period, including purchases, contributions from own production and food items offered to members as gifts. Data on food quantities consumed in restaurants, canteens and similar establishments are, however, not collected. Trained interviewers visit the households regularly to ensure complete recording. The data collection is accomplished within one year, with due attention to capture seasonal variation in food intake. Information on the demographic and socio-economic characteristics of the household members is also collected, allowing exploratory analyses on the effect of socio-economic determinants on dietary choices ${ }^{16}$.

\section{Integration of national HBS data in the DAFNE databank}

Before being integrated in the DAFNE databank, the food and sociodemographic HBS data are cleaned, managed and harmonised in accordance with the DAFNE methodology ${ }^{1,17}$. The food quantities available for consumption by each household member are calculated by dividing the household availability by the product of the referent time period and the mean household size, without making allowances for inedible parts, preparation losses, spoilage on the plate or food offered to domestic pets, and under the assumption of equal distribution of food during the survey period. Weighting factors are also incorporated, whenever necessary, to accommodate national sampling schemes.

\section{Estimating energy and nutrient availability from bousebold food acquisitions}

The conversion of household food acquisitions into energy and nutrient values does not always imply a direct application of food composition data, since HBSs often provide information on the level of food groups rather than individual food items. Adjustments are therefore necessary to address specific requirements and meet the constraints posed by the characteristics of the HBS food data.

In the analysis undertaken in the context of the EUsupported DAFNE IV project, four different approaches were tested ${ }^{18}$. All approaches aimed at estimating the nutrient content of aggregated HBS food codes, but allowed for variations in the dietary data available in a country. They also varied in the degree of effort required for their application, with the first one being the least and the last the most demanding. More specifically:

- Approach 1 - Determination through one food item, representative of the group. The nutrient content of aggregated food codes was defined through the nutrient content of one representative food item, which was arbitrarily selected in each country by a group of nutrition experts. The approach is based on the assumption that all items classified under one food code are compositionally similar and that the selected food item is the one most frequently consumed by the respective population.

- Approach 2 - Determination through all food items classified under the group (unweighted mean). The nutrient content of the aggregated codes was calculated as the unweighted mean of the composition of all food items grouped in each code. Through this approach the eating habits and preferences of a population are downgraded, as in every food code popular food items are treated in the same manner as the less common ones.

- Approach 3 - Determination through all food items classified under the group (weighted mean, with weights being defined by experts). Differently to Approach 2, the nutrient content of the aggregated food codes was calculated as a weighted mean of the composition of the food items grouped in the particular code. Factors assigning the relative importance of each food item in the corresponding code were used to allow for the eating habits and preferences of the population and were determined by a group of nutrition experts, who examined the list of items in each aggregated code and discussed their expected contributions. Where available, information retrieved from national market shares or from food balance sheets $^{19}$ (e.g. share of corn oil among vegetable oils) was also considered.

- Approach 4 - Determination through all food items classified under the group (weighted mean, with weights being defined according to data collected in individual dietary surveys). Similarly to Approach 3, the content of the aggregated food codes was calculated as a weighted mean of the composition of food items grouped in this code. However, in this approach, factors assigning relative contributions were systematically estimated using data collected through national, individual-based dietary surveys undertaken during a similar time period. 


\section{Selection of the food composition data}

To allow for comparisons with individual-based data on energy and nutrient intakes available at country level, national food composition tables were used. The German data were analysed on the basis of the Bundeslebensmittelschlüssel (BLS, version II.3) ${ }^{20}$ and the Greek data were analysed using the composition tables of foods and Greek dishes ${ }^{21}$, supplemented by data available in the tables on the composition of Greek fish ${ }^{22}$ and the tables on the composition of Greek cheeses ${ }^{23}$.

The factors, estimated according to the four approaches previously described, were applied to the food composition data and tables of nutrient conversion factors were generated. These tables were integrated into a software interface program written in Microsoft Visual FoxPro and developed at the DAFNE coordinating centre. The program allows the direct estimation of daily nutrient availability, making use of data on food availability retrieved from the DAFNE databank.

\section{Evaluating the nutrient estimates}

In accordance to methods applied in national settings $^{11,12,14}$, a conventional deduction of $10 \%$ for wastage of edible food in the home was applied in the HBS data. The results obtained after application of the nutrient conversion factors and the 10\% wastage factor were compared with published nutrient intake data.

In the case of Germany, estimates obtained from the HBS were compared with data collected through the Bavarian Food Consumption Survey ${ }^{24}$. The survey was carried out in 2002/03 and assessed the food intake of approximately 900 participants aged 14 years or older. Dietary information was collected through computer-aided telephone interviews to obtain three repeated 24-hour recalls per participant, using an amended version of EPIC-SOFT ${ }^{25}$, the software program developed in the European Prospective Investigation into Cancer and Nutrition (EPIC).

In the case of the Greek data, HBS-derived daily nutrient availability was compared with intakes estimated from data collected through the Greek segment of the EPIC study ${ }^{26}$. The study sample consisted of 28572 adult and elderly volunteers, recruited during a 5-year period (1994 to 1999) from around Greece; their dietary intake over the past year was assessed through a validated, semiquantitative, interviewer-administered food-frequency questionnaire $^{27,28}$.

To increase the comparability of the HBS-derived nutrient data and those collected through the individual nutrition surveys in the two countries, sub-samples of the German and Greek HBSs were used. Specifically, the German HBS sample used in the comparisons consisted of households with members aged 14 years and over and residents of the southern German state of Bavaria. In correspondence to the characteristics of the Greek EPIC population, the Greek HBS sample consisted of households with members aged 18 years and over. Comparisons were made on the basis of the daily intakes of energy and macronutrients (protein, fat - saturated, monounsaturated and polyunsaturated fatty acids, carbohydrate and alcohol).

The results of the comparisons were presented and discussed in several working sessions, also attended by officials from the United Nations' Food and Agriculture Organization and the Department for Environment, Food and Rural Affairs (UK), both having long experience in nutrient estimations using this type of data.

In summary, participants concluded that the first two approaches may provide invalid estimates and that common practice should make use of Approaches 3 and 4, with Approach 4 (systematic determination of weighting factors by referring to external data collected in national individual dietary surveys) being the preferred method and Approach 3 (arbitrary determination of weighting factors by a group of nutrition experts) being used when corresponding data from national individual dietary surveys are not available ${ }^{18}$. However, the need to be able to apply a common methodology to all datasets available in the DAFNE databank confined the selection to the second-best approach.

Comparisons between the values obtained after application of the selected method (factors determined by a group of nutrition experts) to sub-samples of the HBS food data and estimates derived from individual-based nutrition surveys are given in Table 1. In both countries, the HBS-based estimates are higher than the intake data with the exception of alcohol, pointing to the important contribution of eating out in its daily intake. However, the differences seem to level out when the data are presented in terms of each nutrient's contribution to daily energy intake.

Furthermore, we evaluated correlations between macronutrient intakes in Germany and Greece. In Germany data were available for five regions in the state of Bavaria, whereas in Greece data were available for nine regions in the whole country. The data were not congruent nor did they refer, in the case of the HBS data, to single individual households, so that the conditions for validation were far from optimal. In Germany energy intake in the HBS and individually derived data were positively associated ( $r=0.56, P=0.33$ ), but correlations between energyproviding nutrients were not mutually adjusted because of the scarcity of degrees of freedom. In Greece, by contrast, energy intake in the HBS and the EPIC data were inversely associated $(r=-0.26, P=0.50)$ and the availability of more degrees of freedom allowed us to control for energy intake in evaluation of the associations between the two estimates (HBS-based and individually derived) of macronutrient intake. The interpretability of the findings is hindered by the underlying noncongruence and the small number of correlation points (five in Germany, nine in Greece). In Germany correlation 
Table 1 Energy and nutrient intakes and percentage contribution to total energy (\%E) estimated in sub-samples of the national household budget surveys (HBS) and through individual nutrition surveys in Germany and Greece (unit person ${ }^{-1}$ day $^{-1}$ )

\begin{tabular}{|c|c|c|c|c|}
\hline & \multicolumn{2}{|c|}{ Germany } & \multicolumn{2}{|c|}{ Greece } \\
\hline & $\begin{array}{c}\text { Sub-sample of the } \\
1998 \text { HBS }^{*}\end{array}$ & $\begin{array}{c}\text { The Bavarian } \\
\text { Survey }(2002 / 03)\end{array}$ & $\begin{array}{c}\text { Sub-sample of the } \\
1998 / 99 \text { HBSt }\end{array}$ & $\begin{array}{c}\text { The Greek EPIC } \\
\text { study }(1994-1999) \ddagger\end{array}$ \\
\hline Energy (kcal) & $3317.0(48.7)$ & $2000.1(22.3)$ & $2627.6(20.3)$ & $2096.1(4.1)$ \\
\hline Protein $(\mathrm{g})$ & $135.6(2.3)$ & $72.7(0.9)$ & $87.5(0.4)$ & $74.5(0.1)$ \\
\hline Protein (\%E) & $16.14(0.09)$ & $14.96(0.11)$ & $14.75(0.05)$ & $14.29(0.01)$ \\
\hline Fat $(\mathrm{g})$ & $131.6(2.2)$ & $82.0(1.2)$ & $141.3(1.9)$ & $107.3(0.2)$ \\
\hline Fat (\%E) & $34.89(0.18)$ & $35.86(0.24)$ & $43.18(0.15)$ & $45.95(0.03)$ \\
\hline SFA (g) & $47.9(0.7)$ & $33.5(0.5)$ & $33.3(0.3)$ & $30.3(0.1)$ \\
\hline SFA (\%E) & $12.91(0.08)$ & $14.62(0.13)$ & $11.20(0.03)$ & $12.86(0.02)$ \\
\hline MUFA (g) & $48.9(0.9)$ & $29.5(0.5)$ & $74.3(1.4)$ & $51.7(0.1)$ \\
\hline MUFA (\%E) & $12.91(0.07)$ & $12.80(0.11)$ & $21.25(0.12)$ & $22.24(0.02)$ \\
\hline PUFA (g) & $22.2(0.5)$ & $13.6(0.2)$ & $20.5(0.3)$ & $15.8(0.1)$ \\
\hline PUFA (\%E) & $5.73(0.07)$ & $6.05(0.08)$ & $6.23(0.05)$ & $6.77(0.02)$ \\
\hline Carbohydrates (g) & $369.7(5.6)$ & $215.5(2.6)$ & $259.6(1.4)$ & $203.8(0.4)$ \\
\hline Carbohydrates (\%E) & $45.49(0.21)$ & $44.08(0.27)$ & $40.78(0.12)$ & $36.86(0.03)$ \\
\hline Alcohol (g) & $12.4(0.5)$ & $12.7(0.6)$ & $4.6(0.1)$ & $9.4(0.1)$ \\
\hline Alcohol (\%E) & $2.91(0.13)$ & $4.23(0.20)$ & $1.27(0.03)$ & $2.79(0.03)$ \\
\hline
\end{tabular}

SFA - saturated fatty acids; MUFA - monounsaturated fatty acids; PUFA - polyunsaturated fatty acids.

Data are presented as mean (standard error of the mean).

${ }^{*}$ Sub-sample consisting of Bavarian households with adolescent, adult and elderly members (aged 14 years and over).

tSub-sample consisting of households with adult and elderly members (aged 18 years and over).

‡European Prospective Investigation into Cancer and Nutrition.

coefficients (and two-tailed $P$-values) were $r=0.79(0.11)$ for protein, $r=0.44(0.45)$ for carbohydrates, $r=0.88$ (0.05) for saturated fatty acids, $r=0.55(0.34)$ for monounsaturated fatty acids and $r=0.67(0.22)$ for polyunsaturated fatty acids; whereas in Greece correlation coefficients (and two-tailed $P$-values) were $r=0.48$ (0.19), $r=-0.05$ (0.90), $r=0.76$ (0.02), $r=0.59$ (0.09) and $r=0.70$ (0.04), respectively.

\section{Results}

In the light of comparisons between sub-samples of the HBS data and the individually derived data described above, Approach 3 was applied in the total HBS samples and results for the daily individual availability of energy and selected nutrients in Germany and Greece are presented in Table 2. For the estimations, the nutrient composition of aggregated food codes was calculated taking into consideration the proportional contribution of the food items grouped in each code, as defined by a group of nutrition experts. To account for food wasted or spoiled, the $10 \%$ wastage factor was applied in all values.

According to the data presented in Table 2, in the late 1990s the daily individual availability of energy and protein was similar in the two countries. Differences were, however, observed in the case of carbohydrates, with German households reporting a 5 percentage points higher contribution of carbohydrates in their daily energy availability. Differences were also evident in the daily availability of lipids, with German households recording lower values for total lipids but higher values for saturated fatty acids (14\% of the daily energy availability).
Table 2 Mean energy and nutrient availability and percentage contribution to total energy (\%E) among nationally representative population samples in Germany and Greece in the late 1990s (unit person $^{-1}$ day $^{-1}$ )

\begin{tabular}{lccc}
\hline & Germany & & Greece \\
\cline { 2 - 2 } & HBS 1998 & & HBS 1998/99 \\
\hline Energy (kcal) & $2216.8(23.0)$ & & $2330.5(13.6)$ \\
Protein (g) & $75.7(0.7)$ & & $78.5(0.3)$ \\
Protein (\%) & $13.99(0.03)$ & & $14.87(0.03)$ \\
Fat (g) & $87.6(0.4)$ & & $124.2(1.3)$ \\
Fat $(\% \mathrm{E})$ & $35.37(0.07)$ & & $42.83(0.10)$ \\
SFA (g) & $34.7(0.2)$ & & $30.2(0.2)$ \\
SFA (\%E) & $14.19(0.03)$ & & $11.45(0.02)$ \\
MUFA (g) & $32.3(0.2)$ & & $64.3(0.9)$ \\
MUFA (\%E) & $13.03(0.03)$ & & $20.59(0.08)$ \\
PUFA (g) & $15.0(0.1)$ & & $17.9(0.2)$ \\
PUFA (\%E) & $5.91(0.03)$ & & $6.22(0.03)$ \\
Carbohydrates (g) & $255.7(4.5)$ & & $232.3(0.9)$ \\
Carbohydrates (\%E) & $46.14(0.05)$ & & $41.10(0.08)$
\end{tabular}

HBS - household budget survey; SFA - saturated fatty acids; MUFA monounsaturated fatty acids; PUFA - polyunsaturated fatty acids. Data are presented as mean (standard error of the mean).

Monounsaturated fatty acids were, on the other hand, important contributors in the Greek diet (21\% of the daily energy availability). It should however be pointed that the share of saturated fatty acids in the Greek diet has increased substantially since the 1960s, when the first data on the diet of Mediterraneans were collected, and is now close to the upper recommended level of $10 \%$ of total energy intake ${ }^{29}$.

Figures 1 and 2 present the relative contributions of main food groups to the daily energy and nutrient availability for Germany and Greece, respectively. In these plots, food groups appear in the order in which they 


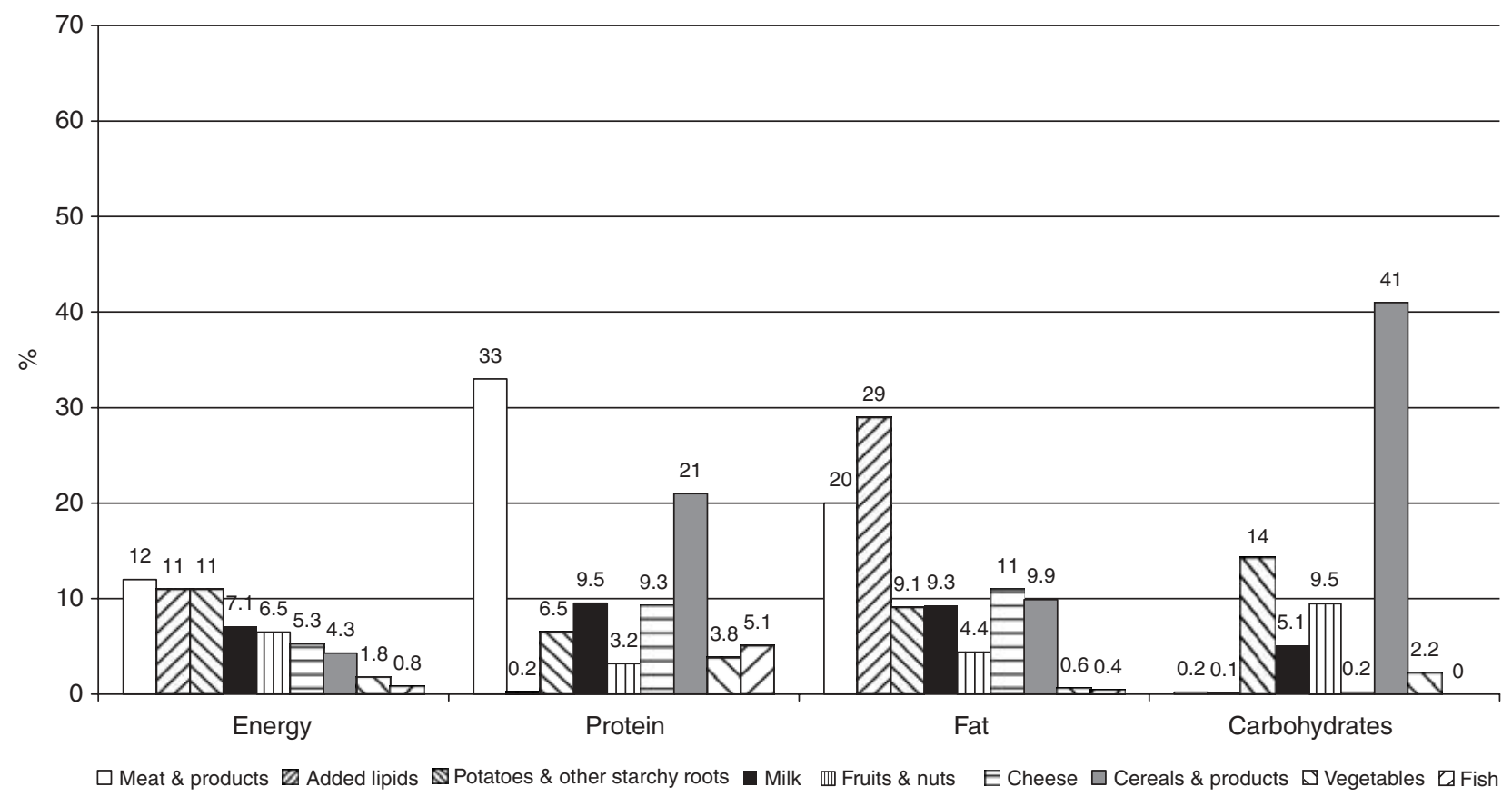

Fig. 1 Percentage contribution of main food groups to the mean daily availability of energy and macronutrients in a nationally representative population sample in Germany, 1998

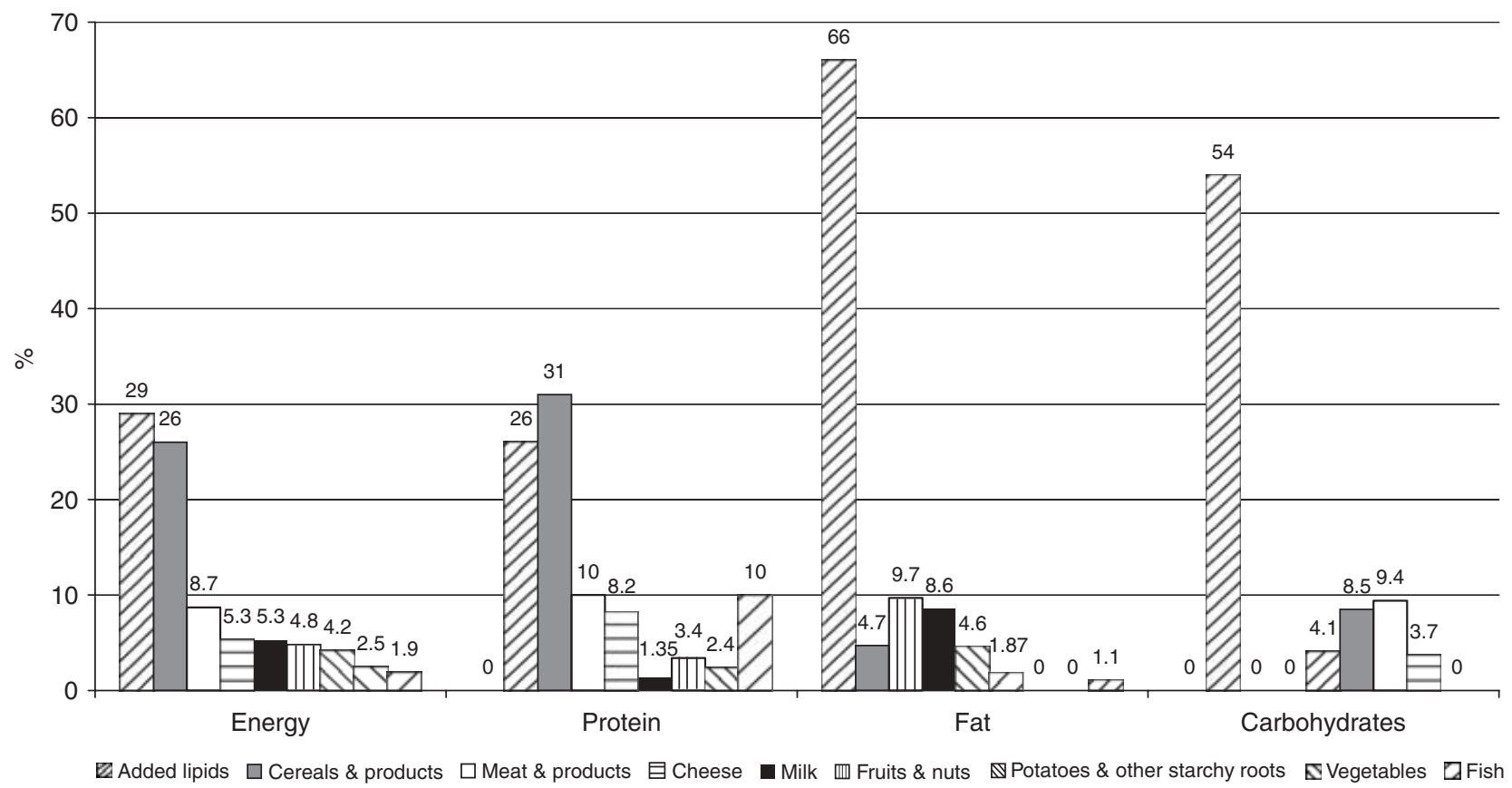

Fig. 2 Percentage contribution of main food groups to the mean daily availability of energy and macronutrients in a nationally representative population sample in Greece, 1998/99

contribute to daily energy availability; a zero value is indicated when a food group does not contribute to the daily availability of the specific nutrient.

Among the food groups presented, meat and meat products, added lipids, potatoes and other starchy roots were identified, in this order, as important energy suppliers in Germany, whereas in Greece the first three energy suppliers were added lipids, cereals and cereal products, meat and meat products. It should however be noted that the energy and nutrient contribution of the 
presented food groups was lower in Germany than in Greece. Important protein sources were meat, cereals, milk and cheese (in Germany and Greece), as well as fish (only in Greece). In both countries, cereals, potatoes, fruits and nuts contributed more than $60 \%$ of the daily carbohydrate availability. Differences were however noted in the contributors of fat availability. As expected, added lipids were the major source of fat in the daily diet of both countries, but their contribution amounted to less than one-third in Germany (29\%) and two-thirds in Greece (66\%). With respect to added lipids, it is also worth noting that although in Greece the contribution of added lipids to the daily fat availability followed a decreasing trend in recent years (from 68\% in 1981/82 to $66 \%$ in 1998/99), the contribution of vegetable oils other than olive oil increased (from 2.1\% in 1981/82 to $8.8 \%$ in 1998/99). Apart from added lipids, meat and meat products and cheese were notable sources of fat in the daily diet of both countries.

\section{Discussion}

A challenge in estimating nutrient availability from HBS data is that the recorded food items are grouped into predefined food codes, which can often be of an aggregated nature. In several cases, the food items grouped in one code are not listed in detail and generic names are used for the description (e.g. food code described as soft cheese with no specific indications or details on which particular types of cheese the households reported consuming). Even if, however, the food items are specified, additional information is required to allow for evaluating the relative importance of each item in the aggregated code. The grouping of food items under generic codes may lead to additional limitations, as it is usually performed to serve the needs of the data collectors (i.e. the officers of statistical institutes) and not of the potential data users (in our case, nutritionists). Elaborate methods in estimating nutrient values based on HBS food data have been applied at national level, but the literature describing the details of these methods is limited. Based on the critical methodological steps presented in ad boc national reports, we developed and evaluated four approaches to deal with the limitations of HBS data and we selected one to be commonly applied to the datasets of two countries. As, however, our intention was to wind up with a methodology that could be applied in the setting of possibly all EU member states, our selection was confined by the variant levels of dietary data available in the countries.

The results obtained after application of the selected method to sub-samples of the German and Greek HBSs were compared with energy and nutrient intake data derived from individual-based dietary surveys. In absolute terms, the HBS-based estimates were higher than the individual-based ones. Nevertheless, the nutrient densities estimated on the basis of the HBS data agree well with those reported in the individual-based dietary surveys. A proper validation of the HBS data would have required assessment of dietary intakes for the same individuals through both the HBS protocol and the methodology of an individual-based dietary survey. Such data, however, were not available. Instead, we have attempted ecological correlations using five group entities in Germany and nine in Greece. The ecological nature of the association, the limited congruence of the population coverage and the scarcity of available degrees of freedom (nine correlation points in Greece and five in Germany) seriously compromise the interpretability of the findings. Nevertheless, the constellation of associations suggests that the HBS data analysed through the methodology proposed in the present paper tend to capture, to a considerable extent, the pattern of nutrient intakes in the underlying populations.

Values presented in Table 2 were derived after application of the same methodology to the total HBS samples. As the estimates presented in this table refer to all household types, including households with infants and children who are expected to have lower intakes than adults and elderly, they are lower than those presented in Table 1. This means that our assumption of equal distribution of food among household members is expected to underestimate the true intake of an adult or elderly person, particularly in households where infants and children are also present. The collection of data on aggregate household consumption is a known limitation of the HBS. There are different methods to estimate the per person food and nutrient availability and these range from a simple division by the number of household members (used in our analysis) to the application of sophisticated statistical modelling for calculating age- and gender-specific values ${ }^{15,30,31}$.

The lack of information on eating at restaurants, canteens and similar establishments is an additional limitation of the HBS and is likely to affect estimations of food intake to a different extent, depending on the age of the household members. Over-purchasing has also been reported as an age-related habit, since it appears as a common characteristic of elderly women living alone ${ }^{30,32}$. As in all dietary data, sources of misclassification operating at different directions also exist in the HBS food data. Their effect, however, may be constant over time and as such they are not expected to impair comparisons over time.

In accordance with methods applied in national settings ${ }^{11,12,14}$, our analysis addressed the lack of information on the quantity of food wasted by assuming that $10 \%$ of all foods - and hence of all nutrients available for consumption - is lost through either wastage or spoilage in the kitchen, on the plate, or fed to domestic pets. Although no recent studies on household food wastage are available in the literature, a classic study in 
the UK reported that waste accounted on average for $6.5 \%$ of the energy intake in summer and $5.4 \%$ in winter, when assessed against the expected usage of food at home $^{33}$. In the same study, the authors reported that considerable quantities of otherwise edible food were given to pets and birds. Food wastage was also reported as being significantly influenced by the composition of the family, with adults wasting more in absolute terms than children, and larger households wasting less per person than smaller ones. Similar observations were also reported in other studies ${ }^{34,35}$. In the light of these findings, the application of the $10 \%$ factor throughout the data seems plausible. For some food items, however, as is the case for vegetable oils and cooking fats, the amount wasted during use (repeated frying for example) can be considerable and possibly higher than $10 \%$.

Our conclusions after comparing HBS-derived values with those estimated through individual-based surveys generally agree with previous publications of similar ecological comparisons, according to which the HBSbased availability values are higher for energy and significantly higher than individual intakes for carbohydrate and fat, probably due to larger wastage associated with the latter ${ }^{36}$. However, when estimates were adjusted to the same energy intake the observed differences diminished. In a study undertaken in Cambridge in which data on households' acquisitions and the daily intakes of their members were jointly collected, there was no significant difference in the nutrient content of purchases and consumption per $1000 \mathrm{kcal}$, with the exception of iron and vitamin $\mathrm{C}^{32}$. In a similar study undertaken in Poland, authors commented that the daily energy and nutrient availability estimated from households' purchases was within $\pm 10 \%$ of their members' intakes estimated using 24-hour recalls. Exceptions were polyunsaturated fatty acids (higher availability estimates), potassium and vitamin $\mathrm{C}$ (higher intake estimates) ${ }^{37}$.

The present paper aims to set the ground for using national HBS data for monitoring the availability of nutrients among representative population samples. Furthermore, the described methodology lays the foundation for the development of a harmonised food composition table to be used in a common between-countries procedure for estimating nutrient availability using HBS data at national or international level. The outcome of current projects related to food composition data for international comparisons, such as the European Food Information Resource (EuroFIR) (www.eurofir.net), could prove useful in the development of a DAFNE food composition table.

\section{Acknowledgements}

Sources of funding: The analysis presented was undertaken in the context of the DAFNE IV project, which was supported by the Health Monitoring Programme of DG-SANCO.

Conflict of interest declaration: The authors have no conflict of interest to declare.

Authorship responsibilities: Each author has participated sufficiently in the work. Authorship was based on substantial contributions to (1) conception and design, (2) analysis and interpretation of data, (3) drafting the article or revising it critically for important intellectual content and (4) final approval of the version to be published.

Acknowledgements: The authors would like to thank Mr Konstantinos Tsiotas for his assistance in the management of the Greek data.

\section{References}

1 Trichopoulou A, Naska A; DAFNE III Group. European food availability databank based on household budget surveys: the Data Food Networking initiative. European Journal of Public Health 2003; 13(3 Suppl.): 24-8.

2 Trichopoulou A, Naska A, Costacou T; DAFNE III Group. Disparities in food habits across Europe. Proceedings of the Nutrition Society 2002; 61(4): 553-8.

3 Naska A, Fouskakis D, Oikonomou E, Almeida MD, Berg MA, Gedrich K, et al.; DAFNE participants. Dietary patterns and their socio-demographic determinants in 10 European countries: data from the DAFNE databank. European Journal of Clinical Nutrition 2006; 60(2): 181-90.

4 European Commission, Directorate General for Health and Consumer Protection. Network for the Pan-European Food Data Bank based on Household Budget Surveys. The DAFNE III project [online]. Available at: http://ec.europa.eu/ health/ph_projects/1999/monitoring/monitoring_project_ 1999_full_en.html \#1. Accessed April 2007.

5 European Commission, Directorate General for Health and Consumer Protection. Network for the Pan-European Food Data Bank based on Household Budget Surveys. The DAFNE IV project [online]. Available at http://ec.europa.eu/health/ ph_projects/2002/monitoring/monitoring_2002_04_en.htm. Accessed April 2007.

6 Naska A, Vasdekis VG, Trichopoulou A, Friel S, Leonhauser $\mathrm{IU}$, Moreiras $\mathrm{O}$, et al. Fruit and vegetable availability among ten European countries: how does it compare with the 'fivea-day' recommendation? DAFNE I and II projects of the European Commission. British Journal of Nutrition 2000; 84(4): 549-56.

7 Trichopoulou A; DAFNE contributors. The DAFNE databank as a simple tool for nutrition policy. Data Food Networking. Public Health Nutrition 2001; 4(5B): 1187-98.

8 Upton PK, Gibney MJ. Nutrient intakes in Ireland in 1980: estimates derived from household expenditure on food. Irish Journal of Medical Science 1987; 156(3): 83-9.

9 Mareschi JP. The purchasing method for the estimation of vitamins and minerals intake of the adult. In: Macdonald I, ed. Monitoring Dietary Intakes. ILSI Monographs. Berlin: Springer Verlag, 1991.

10 Rodriguez-Artalejo F, Banegas JR, Graciani A, HernandezVecino R, del Rey-Calero J. Food supply versus household survey data: nutrient consumption trends for Spain, 1958-1988. European Journal of Epidemiology 1996; 12(4): 367-71.

11 Department for Environment, Food and Rural Affairs. National Food Survey - Datasets. Household nutrient data from 1940 onwards [online]. Available at http://statistics. defra.gov.uk/esg/publications/nfs/. Accessed July 2006. 
12 Department for Environment, Food and Rural Affairs. Family Food - Report on the Expenditure \& Food Survey. Family Food 2001-02; 2002-03; 2003-04 (Annual Reports) [online]. Available at http://statistics.defra.gov.uk/ esg/publications/efs/default.asp. Accessed July 2006.

13 Deutsche Gesellschaft für Ernährung. Ernäbrungsbericht 2004. Rheinbreitbach: Plump, 2004.

14 Department for Environment, Food and Rural Affairs. UK Purchases and Expenditure on Food and Drink and derived Energy and Nutrient Intakes in 2004-05 [online]. Available at http://statistics.defra.gov.uk/esg/statnot/ efsstatsnotDec05.pdf. Accessed July 2006.

15 Gedrich K. Ökonometrische Querschnittsanalysen zum Ernährungsverbalten in Deutschland basierend auf einer Sandwich-Theory of Nutritional Behaviour und den Daten der Einkommens- und Verbrauchsstichprobe 1998. Göttingen: Cuvillier, 2005.

16 Trichopoulou A. Monitoring food intake in Europe: a food data bank based on household budget surveys. European Journal of Clinical Nutrition 1992; 46(Suppl. 5): S3-8.

17 Lagiou P, Trichopoulou A; DAFNE contributors. The DAFNE initiative. The methodology for assessing dietary patterns across Europe using household budget survey data. Public Health Nutrition 2001; 4(5B): 1135-42.

18 European Commission, Directorate General for Health and Consumer Protection. The Data Food Networking (DAFNE) initiative. European Food Availability Databank based on Household budget surveys. Final Activity Report of the DAFNE IV Project [online]. Available at http://europa.eu.int/ $\mathrm{comm} /$ health/ph_projects/2002/monitoring/fp_monitoring 2002_frep_04_en.pdf. Accessed July 2006.

19 Food and Agriculture Organization of the United Nations. FAOSTAT Database, Food Balance Sheets [online]. Available at http://faostat.fao.org/faostat/form?collection $=$ FBS\&Domain $=$ FBS\&servlet $=1$ \&hasbulk $=0 \&$ version $=$ ext $\&$ language $=\mathrm{EN}$. Accessed July 2006.

20 Bundesinstitut für gesundheitlichen Verbraucherschutz und Veterinärmedizin (BgVV). Der Bundeslebensmittelschlüssel (BLS II.3): Konzeption, Aufbau und Dokumentation der Datenbank blsdat. Berlin: BgVV, 1999.

21 Trichopoulou A, Georga K. Composition Tables of Foods and Greek Dishes. Athens: M Parisianou Publishing, 2003.

22 Karakoltsidis PA, Zotos A, Constantinides SM. Composition of the commercially important Mediterranean finfish, crustaceans and molluscs. Journal of Food Composition and Analysis 1995; 8(3): 258-73.

23 University of Crete/Technological Educational Institute of Thessaloniki. Composition Tables of Greek Foods [online], 2003 (in Greek). Available at http://nutrition.med.uoc.gr/ GreekTables/index.htm. Accessed July 2006.

24 Himmerich S, Gedrich K, Karg G. Bayerische Verzehrsstudie (BVS) II Abschlussbericht. München: Technische Universität München, 2004.
25 Voss S, Charrondiere UR, Slimani N, Kroke A, Riboli E, Wahrendorf J, et al. EPIC-SOFT ein europäisches Computerprogramm für 24-Stunden-Erinnerungsprotokolle. Zeitschrift für Ernährungswissenschaft 1998; 37(3): 227-33.

26 Riboli E, Hunt KJ, Slimani N, Ferrari P, Norat T, Fahey M, et al. European Prospective Investigation into Cancer and Nutrition (EPIC): study populations and data collection. Public Health Nutrition 2002; 5(6B): 1113-24.

27 Gnardellis C, Trichopoulou A, Katsouyanni K, Polychronopoulos E, Rimm EB, Trichopoulos D. Reproducibility and validity of an extensive semi-quantitative food frequency questionnaire among Greek school teachers. Epidemiology 1995; 6(1): 74-7.

28 Katsouyanni K, Rimm EB, Gnardellis C, Trichopoulos D, Polychronopoulos E, Trichopoulou A. Reproducibility and relative validity of an extensive semi-quantitative food frequency questionnaire using dietary records and chemical markers among Greek school teachers. International Journal of Epidemiology 1997; 26(Suppl. 1): S118-27.

29 World Health Organization (WHO). Diet, Nutrition and the Prevention of Chronic Diseases. Report of a Joint WHO/ Food and Agriculture Organization Expert Consultation. WHO Technical Report Series No. 916. Geneva: WHO, 2003.

30 Chesher A. Diet revealed? Semiparametric estimation of nutrient intake-age relationships. Journal of the Royal Statistical Society A 1997; 160: 389-428.

31 Vasdekis VG, Stylianou S, Naska A. Estimation of ageand gender-specific food availability from household budget survey data. Public Health Nutrition 2001; 4(5B): 1149-51.

32 Nelson M, Dyson PA, Paul AA. Family food purchases and home food consumption: comparison of nutrient contents. British Journal of Nutrition 1985; 54(2): 373-87.

33 Wenlock RW, Buss DH, Derry BJ. Household food wastage in Britain. British Journal of Nutrition 1980; 43(1): 53-70.

34 Dowler EA. A pilot survey on domestic food wastage. Journal of Human Nutrition 1977; 31(3): 171-80.

35 Van Garde SJ, Woodburn MJ. Food discard practices of householders. Journal of the American Dietetic Association 1987; 87(3): 322-9.

36 Serra-Majem L, MacLean D, Ribas L, Brule D, Sekula W, Prattala $\mathrm{R}$, et al. Comparative analysis of nutrition data from national, household, and individual levels: results from a WHO-CINDI collaborative project in Canada, Finland, Poland, and Spain. Journal of Epidemiology and Community Health 2003; 57(1): 74-80.

37 Sekula W, Nelson M, Figurska K, Oltarzewski M, Weisell R, Szponar L. Comparison between household budget survey and 24-hour recall data in a nationally representative sample of Polish households. Public Health Nutrition 2005; 8(4): 430-9. 